\title{
INTENSITAS SERANGAN RAYAP PADA Eucalyptus pellita DI AREAL HUTAN TANAMAN INDUSTRI PT. WANA HIJAU PESAGUAN KABUPATEN KETAPANG
}

\author{
(Intensity Of Termites Attacks In Eucalyptus pellita In The Industrial Plantation Forest PT. \\ Wana Hijau Pesaguan, Ketapang Regency)
}

Octo Erwin Simanjuntak, Rosa Suryantini, Nurhaida

Fakultas Kehutanan Universitas Tanjungpura Pontianak. J1. Daya Nasional Pontianak 78124 Email : octoerwin17@gmail.com

Abstract

PT. Wana Hijau Pesaguan developed the Eucalyptus plant in 2017 and had one year old (20172018). Observations Eucalyptus in PT. Wana Hijau Pesaguan was found termites that attacked Eucalyptus tree (Research and Development 2007). One of termites spesieses that had been indentified by this company is Coptotermes curvignathus. However, until now there had not been known intensity of attacks and the level of damage on the Eucalyptus by termies. Besides there was also the lack of scientific information and publications relating to the level of damage and damage by termites in this area.This research aimed to count the intensity of termite attack in E. pellita in PT. Wana Hijau Pesaguan. This research was conducted from August to September 2018 using field survey. Plot samples were taken as many as 24 plots of size $20 \times 20$ $\mathrm{m}$, the sampling intensity was $10 \%$ of the area of $9.4 \mathrm{ha}$. Data analysis in this study used analysis of the level of damage and intensity of the attack. The results showed this, the species of termites that attacked the E. pellita was Macrotermes gilvus. The level of attack were 0 $9.25 \%$ with the average of damage intensity reached $3.21 \%$. It was categorized into mildly damaged. The factors that influenced the occurrence of termite attacks were the amount of trash and wood stumps, trenches, and locations bordering rubber plants and forests around plants.

Keywords: Eucalyptus pellita, the intensity of damage, the level of attack, Termite, Macrotermes gilvus

\section{PENDAHULUAN}

Eucalyptus terdiri atas 500 spesies dan kebanyakan endemik di Australia. Beberapa spesies juga ditemukan di Irian Jaya, Sulawesi, Nusa Tenggara Timur, dan Timor-Timur (Latifah 2004). Rockwood et al. (2008) melaporkan bahwa eucalyptus sudah dikembangkan menjadi salah satu species penting dalam hutan tanaman industri (HTI). Menurut Siregar (1996), eucalyptus mempunyai banyak manfaat yaitu sebagai bahan kayu bakar, hardboard, papan partikel, furniture dan bahan pulp dan kertas.

Produksi pulp dan kertas di Indonesia dilakukan untuk memenuhi kebutuhan kertas di dalam dan luar negeri. Pada tahun 2015, kebutuhan pulp dalam negeri mencapai 7,3 juta ton per tahun dan produk kertas 10,7 ton. Pada tahun 2017 kebutuhan pulp dan kertas meningkat menjadi 17 ton (Kemenperin, 2015). Kebutuhan pulp secara global diperkirakan akan terus meningkat dalam compounded 
annaulgrowth rate (CAGR), yaitu sekitar 2,6\% setiap tahun. Asosiasi Pulp dan Kertas dalam compounded annaulgrowth rate (CAGR), yaitu sekitar 2,6\% setiap tahun. Asosiasi Pulp dan Kertas Indonesia (APKI) menargetkan produksi pulp dapat mencapai 20,4 juta ton/tahun dan kertas sebesar 19,8 juta ton/tahun pada tahun 2020 (APKI 2013). Dengan demikian eucalypus dapat digunakan menjadi alternatif bahan baku pembuatan pulp dan kertas.

Salah satu upaya pemenuhan kebutuhan bahan pulp dan kertas maka tanaman Eucalyptus dikembangkan di Kalimantan Barat secara besar-besaran dalah bentuk hutan tanaman industry (HTI). Ekstensifikasi tanaman eucalyptus dengan sistem monokultur sangat rentan terahadap serangan rayap salah satunya Coptotermes curvignatus. Menurut Irwanto (2006), C. curvignatus merupakan salah satu rayap yang menyerang tanaman eucalyptus dengan tingkat kerusakan mencapai 57,1\%.

PT. Wana Hijau Pesaguan mengembangkan tanaman Eucalyptus pada tahun 2017 dan telah berumur satu tahun. Hasil pengamatan di areal tanaman Eucalyptus PT. Wana Hijau Pesaguan banyak ditemukan rayap yang menyerang pohon Eucalyptus salah satu jenis rayap yang diteliti oleh perusahaan adalah $C$ curvignathus (Riset \& Deplotmen 2017). Namun sampai saat ini belum diketahui intensitas serangan dan tingkat kerusakan yang merusak pohon Eucalyptus dan belum adanya informasi dan publikasi ilmiah yang diketahui intensitas serangan dan tingkat kerusakan rayap di areal tersebut. Oleh karena itu, dilakukan penelitian mengenai intensitas tingkat kerusakan serangan rayap terhadap tanaman Eucalypus di PT. Wana Hijau Pesaguan.

Tujuan dari penelitian adalah untuk memperoleh data tentang tingkat kerusakan yang disebabkan oleh rayap pada tanaman Eucalyptus pellita di areal tanam PT. Wana Hijau Pesaguan Kabupaten Ketapang. Manfaat dari hasil penelitian dapat dijadikan dasar untuk menentukan tindakan pengendalian serangan rayap teradap $E$. pellita berdasarkan tingkat serangannya dan penentuan jenis tanaman untuk penanaman daur berikutnya.

\section{METODE PENELITIAN}

Penelitian dilakukan di areal penanaman Eucalyptus di PT. Wana Hijau Pesaguan Kabupaten Ketapang. Penelitian dilaksanakn pada bulan agustus sampai september 2018 di lapangan dan dilanjut identifikas rayap.

Penelitian dilaksanakan dengan metode survey. Teknis pelaksanaan terdiri atas : (1) Penentuan blok pengamatan secara sistematik sampling, (2) Luas blok pengamatan $20 \times 20$ meter dengan jumlah blok pengamatan 24 buah, (3) Analisa serangan rayap berdasarkan skor serangan rayap berdasarkan Mardji (2003), (4) Rayap yang menyerang tanaman eucalyptus ditangkap dan dimasukkan ke dalam botol yang berisi alkohol (70\%), (6) Data skoring (Tabel 1) yang diperoleh dimasukkan kedalam tally sheet. 
Adapun analisis data yang digunakan unuk menghiung analis tingkat kerusakan yang dikemukakan oleh Tulung (2000) dengan menggunakan rumus.

$$
K=\frac{n}{N} X 100 \%
$$

Keterangan:

$\mathrm{K}$ : Kejadian serangan oleh rayap.

$\mathrm{n}$ : Jumlah tanaman yang terserang oleh rayap.

dimana :

I : intensitas serangan (\%)

$\mathrm{N}$ : Jumlah tanaman yang diamati

$\mathrm{V} \quad$ : Skor tertinggi yang diamati

$\mathrm{X} \quad$ : jumlah pohon yang diamati

$\mathrm{X} 1 \quad$ : jumlah pohon yang terserang ringan (skor 1)

X2 : Jumlah pohon yang terserang sedang (skor 2)
$\mathrm{N}$ : Jumlah tanaman dalam satu plot.

Selanjutnya untuk menghitung intensitas serangan rayap digunakan rumus yang dikemukakan oleh Mardji (2003) sebagai berikut:

$$
\mathrm{I}=\frac{X 1 Y 1+X 2 Y 2+X 3 Y 3+X 4 Y 4}{N . V} \times 100 \%
$$

X3 : jumlah pohon yang terserang berat (skor 3)

X4 : jumlah pohon yang terserang sangat berat/mati (skor 4)

Y1-Y4 :skor 1 sampai 4 dari masing masing tanaman yang menunjukkan gejala dari serangan ringan sampai terserang sangat berat.

\begin{tabular}{|c|c|}
\hline Kondisi Pohon & Skor \\
\hline Tidak terserang tidak ada serangan rayap & 0 \\
\hline $\begin{array}{l}\text { Terserang ringan bagian pohon yang terserang relatif sempit ditandai dengan adanya } \\
\text { kerak tanah pada batang pohon atau kerak tanah berupa alur-alur yang terdapat pada } \\
\text { perakaran dan batang }\end{array}$ & 1 \\
\hline $\begin{array}{l}\text { Terserang sedang bagian pohon yang terserang relatif agak luas ditandai dengan } \\
\text { adanya kerak tanah pada batang pohon atau kerak tanah yang terbentuk dan menutup } \\
\text { batang pohon sekitar } 1 / 2 \text { dari diameter batang }\end{array}$ & 2 \\
\hline $\begin{array}{l}\text { Terserang berat bagian pohon yang terserang relatif luas ditandai dengan adanya } \\
\text { kerak tanah pada batang pohon atau kerak tanah yang terbentuk sudah menutup } \\
\text { batang pohon }\end{array}$ & 3 \\
\hline $\begin{array}{l}\text { Mati kerak tanah pada batang pohon atau kerak tanah yang terbentuk sudah menutupi } \\
\text { seluruh batang pohon dan daun rontok serta tidak ada tanda-tanda kehidupan }\end{array}$ & 4 \\
\hline
\end{tabular}

Tabel 1. Cara menentukan nilai (skor) serangan rayap pada setiap pohon

\section{HASIL DAN PEMBAHASAN}

\section{Idenifikasi rayap}

Hasil identifikasi rayap yang menyerang di areal penanaman eucalyptus di temukan satu spesies, yaitu Macrotermes gilvus, kasta prajurit. Habitat rayap yang di temukan pada penanaman eucalyptus PT. Wana Hijau

Pesaguan terdapat di pohon eucalyptus. M. gilvus yang ditemukan di areal penelitian, memiliki ciri kepala berwarna coklat dan kemerahan, sepasang manibel yang tajam dan simetris (Gambar 1). Ciri-ciri 
tersesebut menyerupai $M$. gilvus yang dijelaskan oleh Nandika et al. (2003). Mereka juga menambahkan bahwa spesies ini sangat agresif dan akan menggigit, ukuran kasta prajurit lebih besar dibandingkan kasta pekerja
(Nandika et al. 2003). Ciri lain yang ditemukan adalah jumlah ruas antena sebanyak 17 ruas, antena ruas ke-3 sama panjang dengan antena ruas ke -2 , ruas ke-3 lebih panjang dengan ruas ke4 (Nandika et al. 2015).

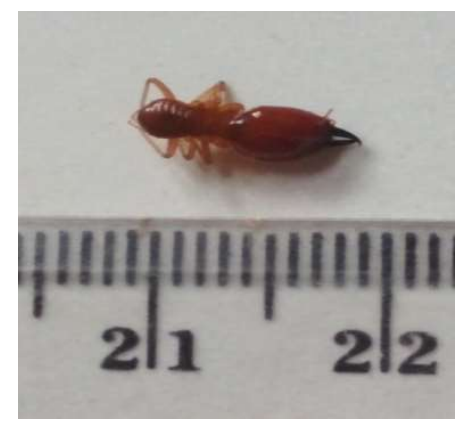

Gambar 1. Macrotermes gilvus

Kejadian Serangan dan intensitas dibandingkan dengan serangan dalam serangan

Hasil penelitian menunjukkan penelitian Irwanto (2006) kejadian serangan mencapai $57,1 \%$. Kejadian bahwa dari 24 petak pengamatan, hanya 20 petak yang terserang oleh rayap dengan kejadian serangan antara 0 9,25\%. Kisaran persentasi kejadian serangan rayap pada eucalyptus termasuk dalam kategori ringan, serangan tidak ditemukan pada 5 petak pengamatan, yaitu petak 1, 5, 10, 15 dan 16. Hal itu dipengaruhi areal tersebut berbatasan dengan jalan menuju lokasi dan tidak ada sampah di areal tersebut.

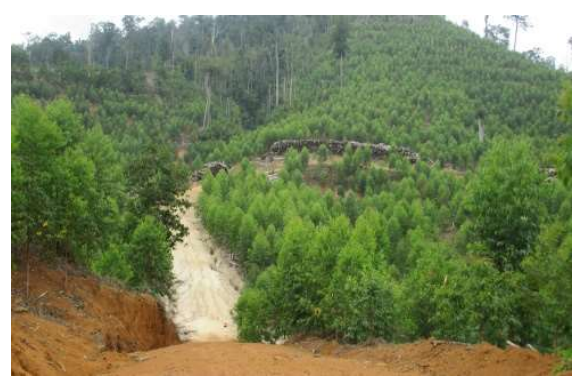

a

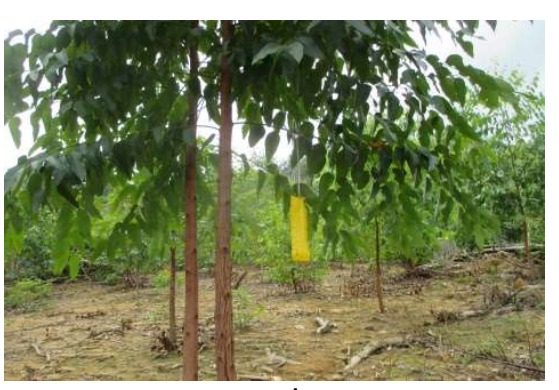

b

Gambar 2. Areal Penanaman a) Areal Berbatasan dengan Jalan; b) Areal Tanam Bersih dari Serasah 


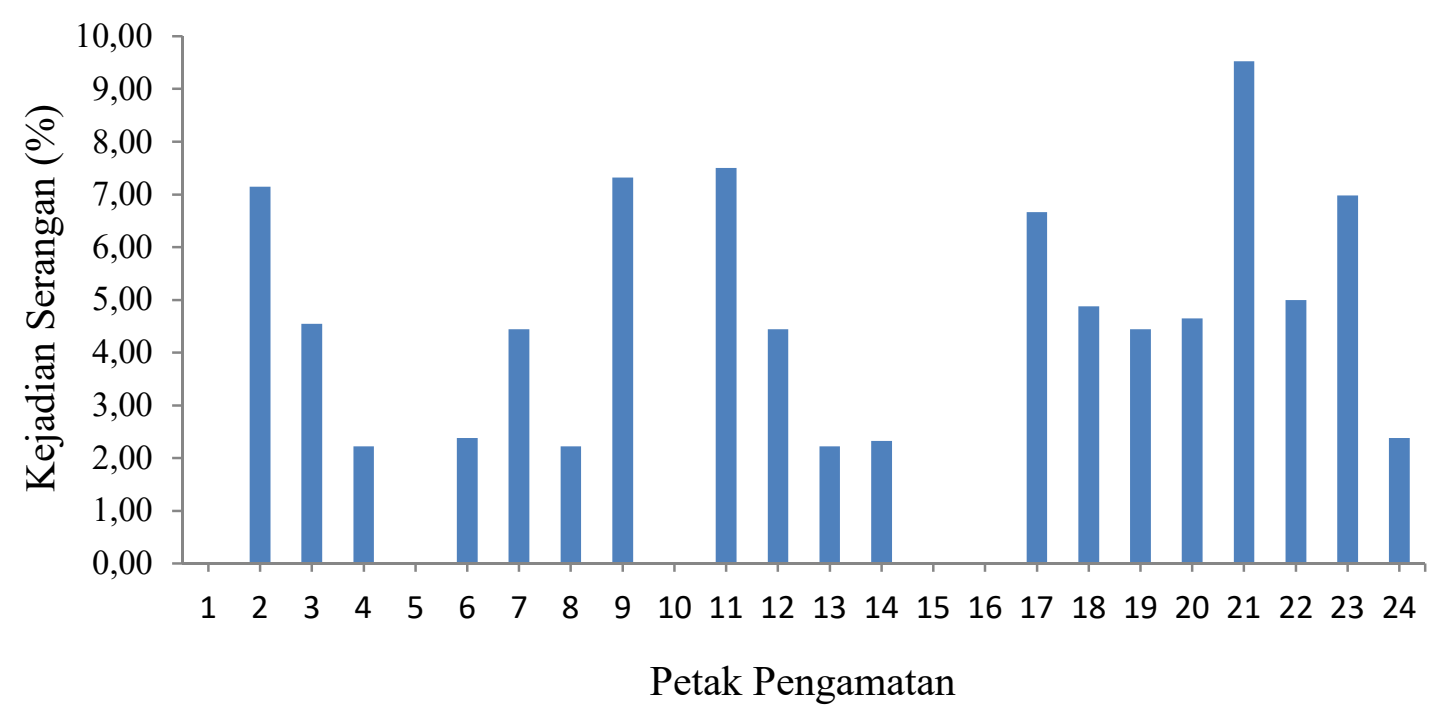

Gambar 3. Kejadian Serangan Rayap Terhadap Tanaman E. pellita

Perbedaan kejadian serangan antar lokasi pengamatan dipengaruhi oleh kondisi lokasi tanaman tidak sama. Kondisi lokasi yang dimaksud adalah lokasi yang berbukit, adanya parit di lokasi tanam, berbatasan dengan kebun karet dan hutan alam dan kebersian lokasi yang berbeda. Tanaman yang berada di dataran rendah lebih banyak diserang oleh rayap dibandingkan tanaman yang berada di dataran tinggi. Hal ini berhubungan dengan suhu dan kelembaban (Pribadi 2010).

Suhu optimum rayap untuk berkembang dan beraktivitas berkisar $15^{0} \mathrm{C}-38^{0} \mathrm{C}$ (Nandika et al. 2003). Suhu di bawah tegakan eucalyptus ditemukannya rayap berkisar antara $24^{0}$ $\mathrm{C}-31^{\circ} \mathrm{C}$ dengan kelembaban optimum adalah 75 - $81 \%$. Selain suhu, kelembaban juga mempengaruhi perkembangan dan distribusi rayap (Pribadi 2010). Semakin tinggi kelembapan maka semakin tinggi serangan rayap dimana kelembaban optimum bagi perkembanga rayap adalah 75-90\% (Ngatiman 2010). Kondisi tersebut dipengaruhi oleh banyaknya serasah dari daun-daun kering dan bekas tunggul kayu di lokasi penelitian.

Intenistas serangan pada setiap petak pengamatan berkisar antara 0 7,7 \% (Gambar 3) sehingga rata-rata intensitas serangan hanya 3,21 \%. Intensitas serangan ini dikategorikan rusak ringan. Secara terperinci, dari 1035 pohon yang diamati hanya 39 pohon yang terserang, dan dari 39 pohon hanya 28 pohon dalam kondisi mati, 2 pohon terserang berat, 6 pohon terserang ringan. 


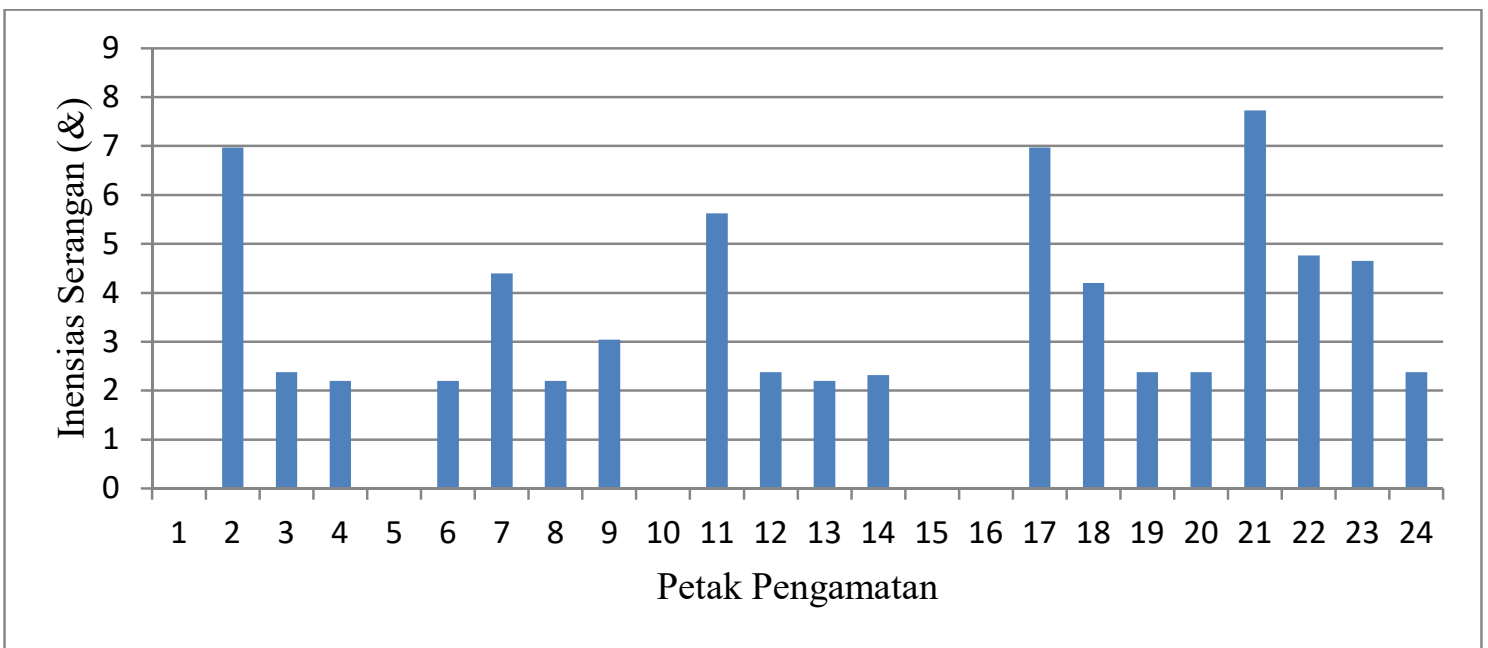

Gambar 4. Intensitas Serangan Rayap Tanaman E. pellita

Rendahnya intensitas serangan rayap dikarenakan diameter pohon yang masih kecil. Nandika et al. (2015) menjelaskan salah satu faktor yang mempengaruhi intensitas serangan rayap adalah kandungan selulosa. Semakin besar diameter pohon maka semakin tinggi kandungan selulosanya.

\section{Kesimpulan}

1. Jenis rayap yang ditemui di lokasi penelitian di tanaman eucalyptus yaitu Macrotermes gilvus dari famili termitidae.

2. Tingkat kejadian serangan rayap terjadi pada 19 petak dari 24 petak pengamatan dengan tingkat kejadian serangan paling tinggi $9,52 \%$ dan kejadian serangannya paling banyak terjadi pada diameter pohon 3-5 cm.

3. Intensitas serangan rayap yaitu 3,21\% dikatagorikan kedalam kondisi tumbuhan rusak ringan.

Saran

Serangan rayap di kawasan penanaman eucalyptus meskipun masih dikategorikan ringan, tetapi tetap memerlukan perhatian dalam hal pengendalian sebelum serangan rayap tersebut meluas yang dapat mengakibatkan kerusakan terhadap tanaman eucalyptus makin parah. Salah satu usaha pengendalian dini adalah perlunya pengelolahan lahan yang bersih atau sesuai dengan standart oparasional prosedur (SOP) yang berlaku untuk mencegah atau mengurangi resiko serangan rayap.

\section{Daftar Pustaka}

Asosiasi Pulp dan Kertas Indonesia (APKI). 2013. "Pulp dan Paper: Industri Kertas dan Bubur Kertas Genjot Produksi”. http:/www.apki.net. [ 05 Nov 2018].

Irwanto. 2006. Penilaian Kesehatan Hutan Tegakan Jati (Tectonagrandis) Dan Eucalyptus (Eucalyptuspellita) Pada Kawasan Hutan Wanagama. Universitas Gajah Mada Yogyakarta.

Kementerian Perindustrian. 2015. Kebutuhan Kertas Domestik Meningkat. Jakarta: Kementerian Perindustrian. 
Latifah S. 2004. Pertanaman dan Hasil Tegakan Eucalyptus grandis di Hutan Tanaman Industri. http://www.libraryusu.ac.id [18 Januari 2018].

Mardji D. (2003). Laporan akhir penelitian dan pendampingan konsultan. Fakultas Kehutanan Universitas Mulawarman terhadap Proyek Rehabilitasi Hutan PT ITCI Kartika Utama di Kenangan.

Nandika D, Rismayadi Y, dan Fara D. 2003. Rayap : Biologi dan Pengendaliannya. Surakarta: Universitas Muhammadiyah Surakarta Press 2003.

Nandika D, Rismayadi Y, dan Fara D. 2015. Rayap : Biologi dan Pengendaliannya, Edisi 2. Surakarta: Universitas Muhammadiyah Surakarta Press 2015 .

Pribadi A. 2010. Pengaruh Temperatur Dan Kelembaban Terhadaptingkat Kerusakan

Daun Jabon
(Anthocephalus Cadamba) Oleh Arthrochista Hilaralis. Jurnal Penelitian Hutan Tanaman.8 (1) : $1-7$.

Riset \& Diplotman (2017). Hama dan Penyakit pada Tanaman Acacia mangium dan Eukaliptus pelita. Ketapang. PT. Wana Hijau Pesaguan

Rockwood D L A W, Rudie S A, Ralph J Y, Zhu, Winand J E. 2008. Energy Product option for Eucelyptus species grown as short rotation woody crops. Internasional Jurnal of Molecular Setences. 9(2) : $1361-1378$

Siregar S Z. 1996. Percobaan Penyulingan Daun Eukaliptus Secara Sederhana. Duta Rimba No. 195 - 196/XX/1996. Jakarta: Perum Perhutani.

Tulung M. 2000. Study of Cacoa Moth (Conopomorpha cramerella) Control in North Sulawesi.

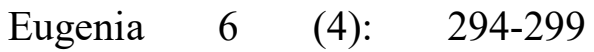

